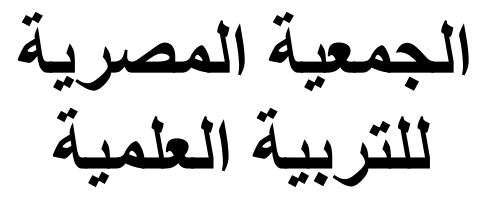

ESST:

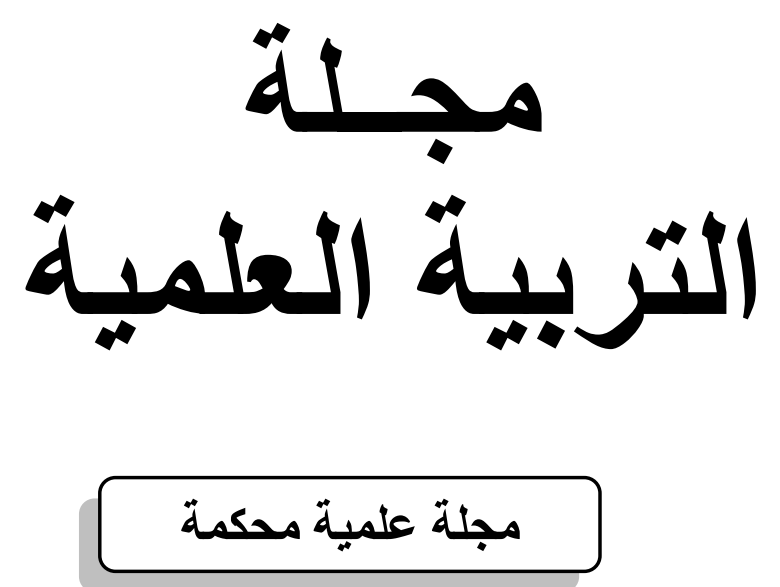

المجلد الثامن عشر العدد:السادس(1) الشهر:نوفمبر السنة: ه 1 • ب م

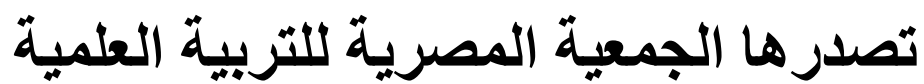

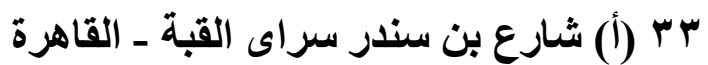

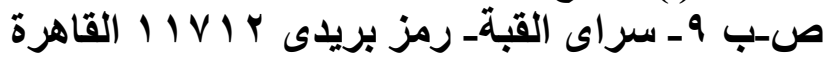

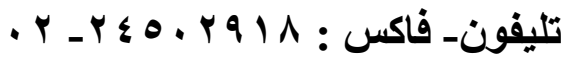




$$
\begin{aligned}
& \text { التربية العمية } \\
& \text { مجلة علمية محكمة } \\
& \text { تصدر عن }
\end{aligned}
$$

الجمعية المصرية للتربية العلمية

$$
\text { رئيس مجلس الإدارة }
$$

أدد/ منى عبد الهادى حسين سعودى رئى

رئبس الأحربير

أ.د/عبد المسيح سمعان عبد المسيح رليّح

"الأراء الواردة بالمجلة لا تعبر بالضرورة عن رأى الجمعية

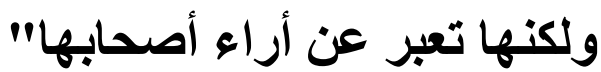

"جميع حقوق النشر محفوظة للمجلة" 


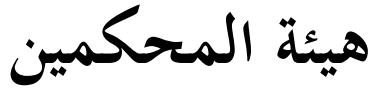

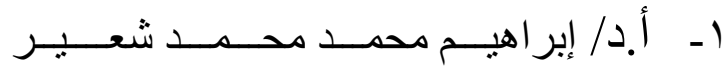

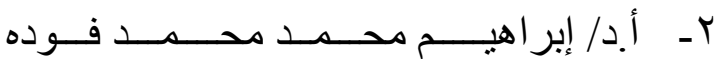

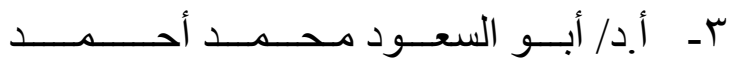

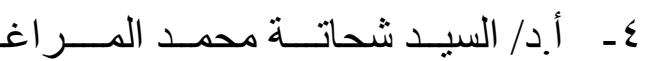

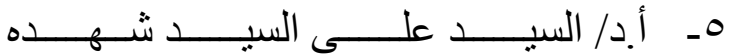

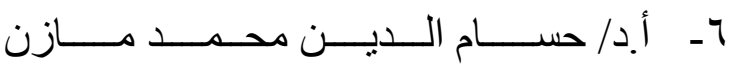

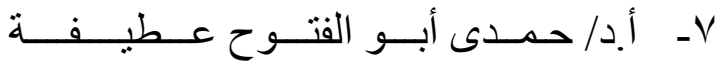

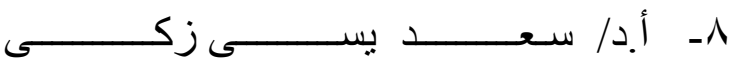

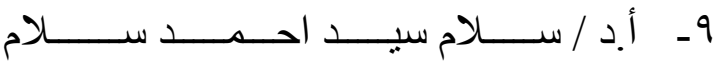

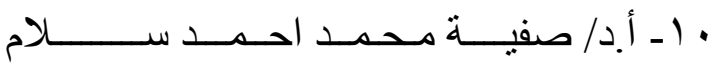

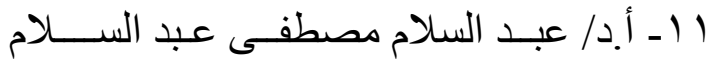

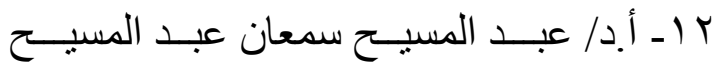

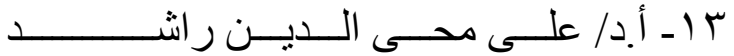

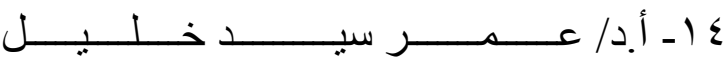

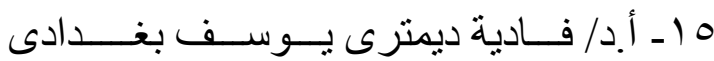

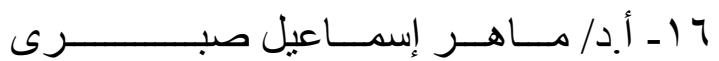

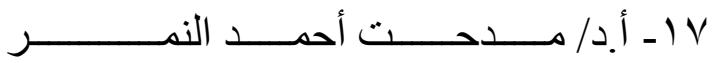

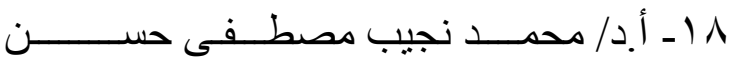

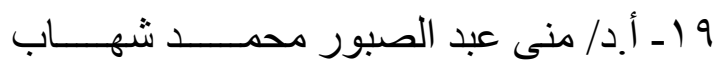

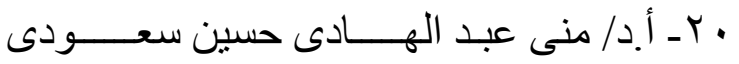




\section{هذا العــــد}

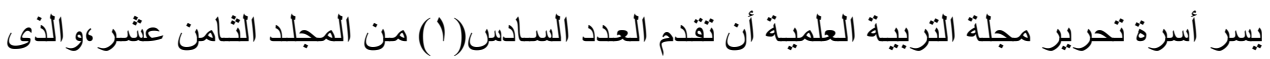

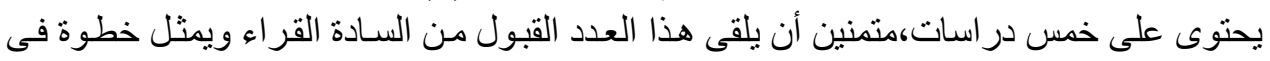
سبيل الإرتقاء بالتربية العلمية وتدريس العلوم فى مصر و العاتئ هذالم العربى.

ويتضمن العدد خمس در اسات شملت مجالات متعددة فى ميدان التربية العلمية:

• الدراسة الأولى للاكتورة: سوزان محمد حسن السيد على بعنوان :

" فاعلية استخدام استراتيجية التعلم المدمج نموذج تناوب المواقع في تدريس مادة الأحياء

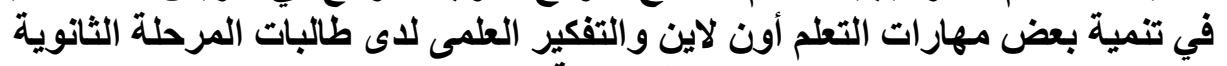
بالسعودية" الإين والتير

• الدر اسة الثانية للاكتورة: عزة عبد الحميد سيد مصطفي بعنوان :

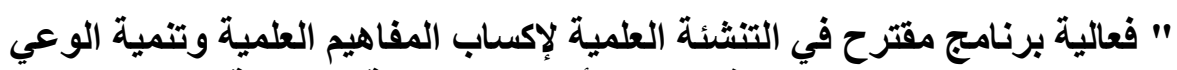
التكنولوجي لتتلاميذ الصف الأول من المرحلة الإبنة الابتدائية"

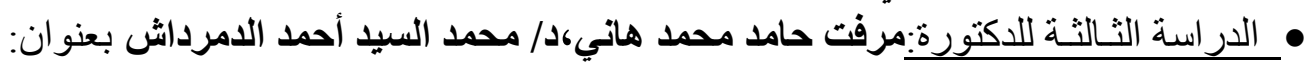

" فاعلية وحدة مقترحة في الرياضيات البيولوجية في تتمية مهارات الفهم العميق لاى طلاب المرحلة الثانويّة" البيولية

• الدر اسـة الر ابعة للاكتورة: نوال محمد شلبى بعنوان:

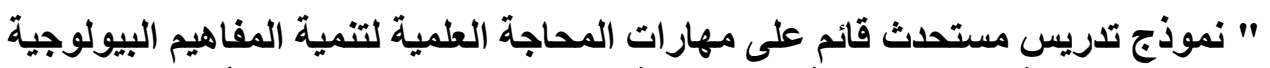

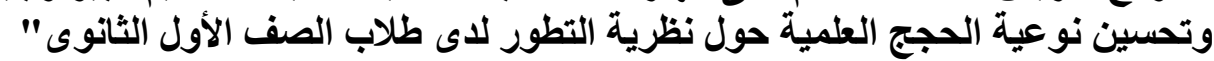

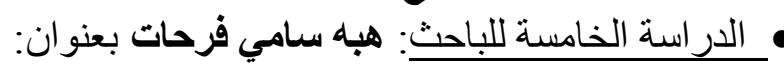

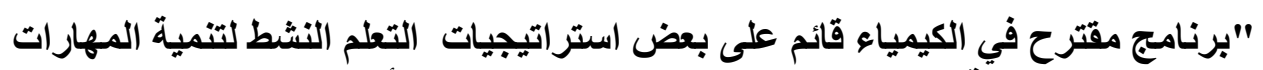

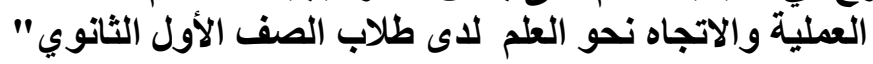

وختاماً نرجو أن يستفيد القارئ من الدراسات العلمية المتضمنة لهذا العدد والتى تتناول

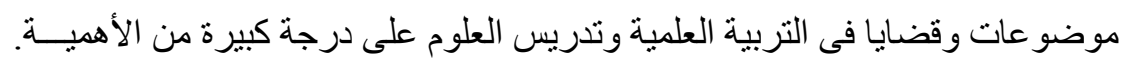
و الله من ور اء القصد ولتصد العوم

\section{رئبس تحرير المجلة}

أبداعب المسيح سمعان عبد المسيح 


\section{المحتويات}

\begin{tabular}{|c|c|}
\hline الصفحة & الموضوع \\
\hline 1 & 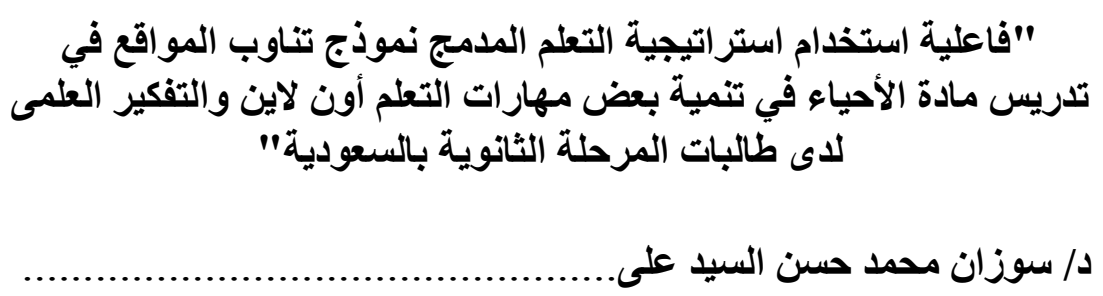 \\
\hline 71 & 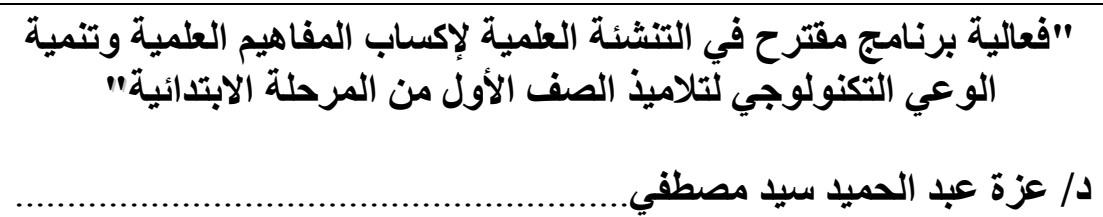 \\
\hline 19 & 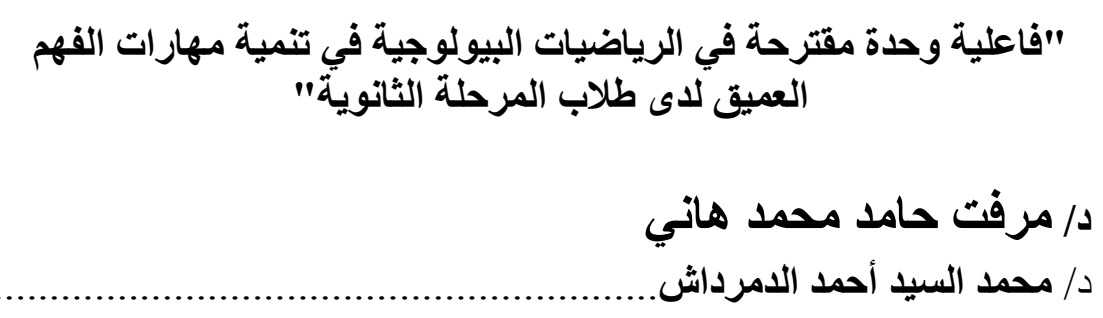 \\
\hline $10 \mathrm{~V}$ & 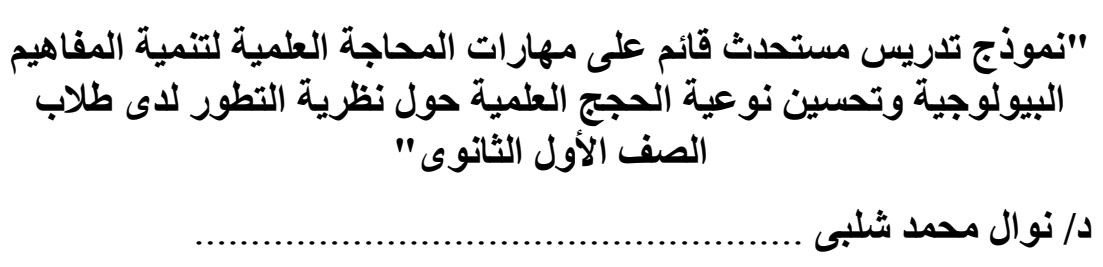 \\
\hline 199 & 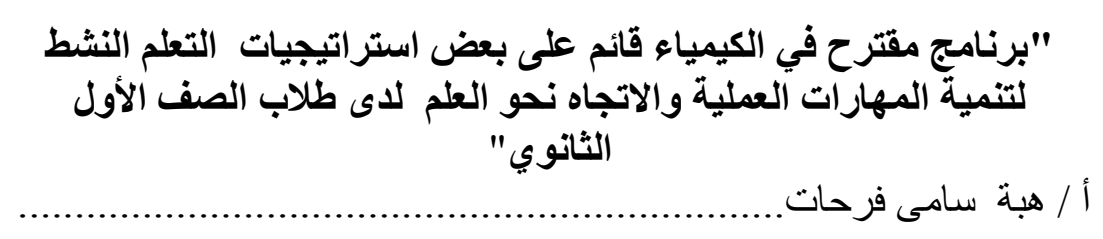 \\
\hline
\end{tabular}




\section{ESSE}

\section{Journal of \\ Science Education}

Vol : 18 N : 6(1) Month : November Year : 2015

Issued By The Egyption Society for Science Education (ESSE)

33 (A) Ibn Sander St. Saraya EL Kobba - Cairo

P.O.-9 Saraya EL Kobba 11712

Tel-fax: 02-24502918 